\title{
GRAMÁTICA \& ESCOLA, UMA ENTREVISTA COM CARLOS FARACO
}

\author{
Izete Lehmkuhl Coelho | Lattes | izete.lehmkuhl.coelho@ufsc.br \\ Universidade Federal de Santa Catarina | CNPq
}

Isabel Monguilhott | Lattes | monguilhott@hotmail.com

Universidade Federal de Santa Catarina

Roberta Pires de Oliveira | Lattes | ropiolive@gmail.com Universidade Federal do Paraná | Universidade Federal de Santa Catarina | CNPq

\section{Introdução}

Carlos Alberto Faraco é professor titular aposentado da Universidade Federal do Paraná, exercendo atualmente a função de professor colaborador dessa Universidade. Fez Graduação em Letras Português/Inglês pela Pontifícia Universidade Católica do Paraná em 1972 e Mestrado em Linguística pela Universidade Estadual de Campinas em 1978. Doutorou-se em Linguística Românica pela University of Salford em 1982. Desenvolveu de 1995 a 1996 estudos de pós-doutorado em Linguística na University of California. Em 1999 recebeu o prêmio paranaense de Ciência e Tecnologia, da Secretaria Estadual de Ciência e Tecnologia e, em 2016, o prêmio Antenor Nascentes, da Academia Brasileira de Filologia.

Em 2005, foi designado pelo Ministro da Educação membro da Comissão para Definição da Política de Ensino-Aprendizagem, Pesquisa e Promoção da Língua Portuguesa. Através do Decreto de 24/03/2010 - DOU 25/03/2010, foi designado membro da Delegação Brasileira à Conferência Internacional sobre o Futuro da Língua Portuguesa no Sistema Mundial, promovida pela CPLP- Comunidade dos Países de Língua Portuguesa. Atualmente, coordena a Comissão do Brasil junto ao Instituto Internacional de Língua Portuguesa (IILP).

Atua na área de Linguística, especialmente com questões relacionadas ao ensino de português, à norma linguística e à história do pensamento linguístico. Publicou vários livros entre os quais se destacam em âmbito nacional: Norma culta brasileira: desatando alguns nós, Linguagem escrita e alfabetização, História Sociopolítica da Língua Portuguesa e Para conhecer norma linguística - este último em coautoria com a professora Ana Zilles.

Tem vasta experiência na formação de professores e na produção de material didá- 
tico tanto para o ensino básico como para o ensino superior. Uma de suas coleções didáticas está no Programa Nacional do Livro Didático (PNLD) desde 2005. Nessa atividade de produção de material, segundo Faraco, os livros espelham suas "crenças e práticas pedagógicas”. Defende que é preciso pensar sobre a língua, sobre o funcionamento estrutural da língua, ao mesmo tempo em que as práticas de leitura, de escrita e de oralidade são desenvolvidas em sala de aula.

\section{Entrevista}

Coelho, Monguilhott e Pires de Oliveira: Os estudos gramaticais atuais entendem gramática como a habilidade de usar adequadamente os recursos linguísticos, o que inclui entre outros a habilidade para perceber e avaliar diferentes variedades linguísticas e para adquirir uma outra gramática, e, portanto, aprender a(s) norma(s) culta(s) da língua. Como o senhor entende que seja essa habilidade na dimensão gramatical?

Carlos Faraco: Como linguistas, sabemos que o conhecimento gramatical do falante é, em grande parte, não inteiramente consciente. E acreditamos que torná-lo consciente (pelo menos em parte) é relevante como recurso cognitivo complementar no processo de aprimoramento do domínio das práticas de leitura, escrita e oralidade.

Acho que é claro para nós linguistas e professores que o conhecimento gramatical não é suficiente para o domínio das práticas linguísticas - não é ele por si e em si que garante o domínio dessas práticas. No entanto, percebi, ao longo do meu magistério (em 2019, completo cinquenta anos de sala de aula), que uma reflexão tanto intuitiva quanto sistemática sobre o funcionamento gramatical da língua, desde que devidamente articulada com as práticas, contribui para esse domínio, contribui para um trânsito mais autônomo e seguro pelas próprias práticas.

Essa reflexão tem, claro, várias dimensões. É útil, por exemplo, para o aprimoramento da leitura e da escrita, refletir sobre aspectos da estruturação de um parágrafo ou de um texto. Quanto à dimensão gramatical, penso que merecem especial atenção as questões morfossintáticas. Trata-se aqui de tornar conscientes alguns dos mecanismos com os quais se constroem os períodos simples e complexos, ou seja, a sintaxe que sustenta a produção de sentidos estruturalmente condicionada.

E isso pode ser feito por vários caminhos: observar fatos nos textos orais e escritos; propor regras descritivas para fatos observados; apreciar a organização estrutural em construções ambíguas; exercitar a chamada análise linguística (observar os textos produ- 
zidos pelos próprios alunos com o objetivo de aperfeiçoar a expressão); explorar formas alternativas de dizer e assim por diante.

Esses vários caminhos permitem que se trabalhe com a intersecção do estrutural com o estilístico, ou seja, entre o que é estruturalmente necessário e o que é aberto à escolha. Observo que a dimensão do possível é menos explorada que a dimensão do necessário, o que redunda, muitas vezes, numa compreensão equivocada do funcionamento estrutural da língua, tomando-o como uma camisa de força quando ele é, de fato, um amplo espaço de liberdade.

De qualquer forma, acho que temos ainda muito a fazer nessa questão toda. Talvez possamos dizer que avançamos no quadro conceitual (cf., por exemplo, entre outros, Antunes, 2007 e 2014; Neves, 2006a e 2006b; Pires de Oliveira \& Quarezemin, 2016; Vieira, 2017), mas falta muito ainda quanto à construção de efetivas alternativas didáticas, uma efetiva e sistematizada pedagogia da gramática.

Coelho, Monguilhott e Pires de Oliveira: Em que essa habilidade pode ajudar no ensino de uma nova norma da língua ou uma outra gramática?

Carlos Faraco: Quando se fala do ensino de uma nova norma, acredito que se está fazendo referência a uma das tarefas que tradicionalmente assumimos caber à escola - ensinar $\mathrm{a}(\mathrm{s})$ norma(s) socialmente esperada(s) em contextos formais, monitorados, de fala e escrita. Essa(s) norma(s) costuma(m) ser denominada(s), no discurso escolar, na mídia e mesmo no senso comum, indistintamente pelas expressões norma-padrão ou norma culta. Sempre no singular - o que é, por si só, um problema, considerando que, nesse nível formal, monitorado do uso da língua, há, de fato, um leque de normas e não uma norma única. Bastaria lembrar aqui alguns exemplos dessas diferenças para deixar claro o meu argumento. Na norma culta falada no Brasil é de frequência quase universal a chamada oração relativa cortadora (Este é o livro que eu mais gostei), enquanto na norma culta escrita ela é ainda de baixa frequência; na norma culta falada, raramente se usa os pronomes oblíquos de terceira pessoa $(o, a, o s, a s)$, ainda bastante frequentes na norma culta escrita.

Vale lembrar também que, entrecruzando com a fala e a escrita, há variação condicionada pelos gêneros do discurso (escreve-se uma crônica esportiva num estilo mais coloquial do que um artigo de análise econômica, por exemplo); e pelos registros (não se relata um voto no Supremo Tribunal Federal do mesmo modo como se defende uma opinião numa assembleia de condomínio). 
Por outro lado, a indistinção terminológica entre norma-padrão e norma culta (que, no entanto, não se esgota nestas duas expressões, conforme mostrou o prof. Marcos Bagno em seu artigo "Variação, avaliação e mídia: o caso do ENEM" - Bagno, 2015) precisa ser, segundo acredito, superada criticamente, ou seja, é preciso fazer, no Brasil, a distinção entre a norma-padrão e a norma culta. Da nossa história sociolinguística resultou o que Celso Cunha chamava de dualidade de normas: temos uma norma praticada pelos chamados falantes cultos em contextos formais (e a esta deveríamos nos referir pela expressão norma culta) e outra norma que é prescrita pela tradição normativa, que, no fundo, estipula a norma portuguesa do século XIX como referência. A esta deveríamos dar o nome de norma-padrão.

Há ainda um outro complicador nessa situação toda: como a norma-padrão nunca conseguiu se estabelecer efetivamente no Brasil, construiu-se, com o tempo, um discurso normativo estreito e categórico (a que tenho dado o nome de norma curta). Enquanto os gramáticos mais qualificados filológica e linguisticamente já apresentam a norma-padrão de um modo mais flexível (até para não excluírem como referência do chamado bom uso os principais escritores modernos brasileiros), o que predomina ainda, infelizmente, no ensino, no trabalho dos revisores, no discurso da mídia, nas provas de concursos são os manuais que engessam as prescrições (quando não inventam regras para as quais não há qualquer respaldo no uso culto efetivo).

Noto que os professores de português se apegam muito à norma curta. Isso ocorre, provavelmente, porque o discurso categórico e dogmático lhes dá segurança. Na falta de uma formação mais consistente, capaz de orientar um pensamento mais flexível sobre a língua, as asserções categóricas, não admitindo alternativas (mesmo que correntes nos usos cultos), pondo a dinâmica da língua num trilho estreito e rígido, parecem oferecer um chão seguro para essa tarefa de ensinar uma nova norma, embora os resultados sejam pífios.

Então, antes de mais nada, quando falamos em ensino de uma nova norma, precisamos desenvolver um conceitual mais adequado. Em primeiro lugar, superar a indistinção terminológica (e o decorrente caos terminológico). Em segundo lugar, incorporar no nosso conceitual a ideia de que os usos cultos variam de acordo com a modalidade oral ou escrita e de acordo com os gêneros e registros do discurso. Em terceiro lugar, temos de fazer um trabalho (técnico e político) de aproximação da norma-padrão com os usos cultos. E, por fim, temos de combater sistematicamente a norma curta.

São grandes pré-requisitos para construirmos uma (mais que indispensável) peda- 
gogia da variação linguística e, no interior desta, uma pedagogia das normas-padrão/cultas. Com isso quero dizer que, ao lado da reflexão sobre o funcionamento estrutural da língua, há a necessidade de se desenvolver também uma reflexão sobre o funcionamento social da língua: entender a variação geográfica e social (alcançando a crítica sistemática aos preconceitos linguísticos); e compreender os sentidos sociais dos diferentes níveis de fala e escrita, incluídos aqui os sentidos sociais dos usos cultos.

Para desenvolver essa ampla sensibilidade sociolinguística e adquirir autonomia e segurança no trânsito entre os diferentes níveis de fala e escrita, é preciso aprender a comparar as diferentes variedades, percebendo que todas elas são gramaticalmente organizadas, embora sejam diferentemente organizadas, ou seja, todas têm gramática, mas comportam regras diferentes. O núcleo dessa comparação será a morfossintaxe, mas também deverá alcançar o léxico e, eventualmente, a pronúncia.

Em suma, acredito que o domínio de uma nova norma passa pela compreensão de seu sentido social e também pelo estudo gramatical comparativo.

Coelho, Monguilhott e Pires de Oliveira: O senhor acredita que seja importante levar essa discussão para a escola? Por quê?

Carlos Faraco: Sim, porque o ensino de português tem muitas dimensões e é preciso compreender cada uma delas bem como suas articulações. Não tenho dúvida de que o centro do ensino devem ser as práticas de leitura, escrita e oralidade. Nesse sentido, acompanho o que defendia Jan Comênio, no seu Didática Magna (livro publicado em 1627): língua não se aprende na gramática, mas nos bons escritores, ou seja, aprende-se a língua na língua em uso e usando a língua. No entanto, defendo também que se aprenda a pensar sobre a língua. Nesse sentido, sigo o que defendia Marco Fábio Quintiliano em seu Institutio Oratoria (obra publicada em 95 d.C.): o estudo da gramática (livre do que é inútil, dizia ele, sugerindo que é preciso selecionar os temas e não ambicionar um saber enciclopédico) tem seu lugar como atividade complementar e não central. Trata-se de refletir sobre o funcionamento estrutural da língua ao mesmo tempo em que se desenvolvem as práticas de leitura, escrita e oralidade.

Além disso, trata-se também de refletir sobre o funcionamento social da língua. São essas dimensões reflexivas, quando devidamente articuladas com as próprias práticas, que contribuem para o aprimoramento do domínio das práticas na medida em que tornam conscientes tanto os mecanismos estruturais que sustentam a produção de sentidos quanto os valores sociais agregados à variação linguística. 
Coelho, Monguilhott e Pires de Oliveira: Em que aspectos o senhor acredita que a linguística pode contribuir para a escola?

Carlos Faraco: Entendo que a linguística contribui indiretamente para o ensino de português. Por ser a disciplina científica que tem a linguagem verbal e as línguas históricas como objeto, é ela que nos fornece as balizas sistemáticas para a compreensão das inúmeras faces do nosso objeto. No entanto, não defendo que se transponha a linguística, pura e simplesmente, para o ensino escolar. Não cabe ensinar as teorias linguísticas na escola, mas sustentar nossas práticas pedagógicas no saber produzido pela linguística. Um dos grandes desafios que nos acompanham como professores de português é saber, por exemplo, como organizar uma pedagogia da variação linguística, tendo no horizonte o muito que sabemos sobre a realidade sociolinguística. Não se trata de dar aula de teoria variacionista stricto sensu na escola básica, mas de trabalhar pedagogicamente com a variação linguística tendo a teoria sociolinguística como substrato.

Coelho, Monguilhott e Pires de Oliveira: Como o senhor avalia o trabalho que a escola vem desenvolvendo com a gramática? O senhor acredita que houve mudança nos últimos anos?

Carlos Faraco: Minha impressão é de que não houve mudanças significativas. Há, certamente exceções. No geral, porém, a escola continua seguindo a pedagogia tradicional que, no fundo, tem sua raiz na escolástica medieval. Os conteúdos gramaticais continuam a ser transmitidos como um saber pronto e acabado: introduz-se a terminologia e os respectivos conceitos; dão-se exemplos e parte-se para exercícios de pura identificação. Noto, inclusive, que não chega a haver nem sequer uma seleção de conteúdos. Transpõese o todo da velha gramática (preso à rigidez da NGB) para os livros didáticos.

Afirmo isso a partir da observação do material didático seja o que é ofertado aos professores pelo PNLD-Programa Nacional do Livro Didático, seja o que é ofertado pelos chamados sistemas de ensino. Não se encontram aí propostas inovadoras para o ensino de gramática.

Penso que, em parte, isso reflete o pouco investimento que temos feito para tornar concreta uma nova pedagogia da gramática. Temos sim discutido conceitualmente, mas temos oferecido poucas alternativas efetivas. 
Coelho, Monguilhott e Pires de Oliveira: Quais as experiências vivenciadas na escola com relação ao ensino de gramática que têm dado certo?

Carlos Faraco: Não tenho dados sobre isso. Meu ponto de observação tem sido muito reduzido. Tenho formado opinião com base na análise do material didático disponível e pelo que ouço dos professores. O que fica disso tudo é a impressão de que a escola tem se contentado em reproduzir a pedagogia tradicional. Não tenho feito um levantamento mais sistemático das eventuais experiências escolares inovadoras. Elas certamente existem, mas repercutem pouco ainda.

Na minha experiência docente, pude observar que certas práticas são muito eficazes. Pontuo aqui a análise linguística (pela qual se pode explorar alternativas expressivas e mesmo mostrar aos alunos que, muitas vezes, pequenos arranjos sintáticos são suficientes para alcançar, por exemplo, maior clareza ou maior leveza expressiva); e a montagem de períodos complexos a partir de um conjunto de períodos simples. É um exercício que dá aos alunos muita visibilidade dos mecanismos sintáticos. E é um exercício que costuma agradar porque os alunos se sentem desafiados ao jogo estrutural. $\mathrm{O}$ mesmo se pode dizer do estudo das cadeias de referenciação e dos processos conectores na construção do parágrafo e do texto.

Coelho, Monguilhott e Pires de Oliveira: O senhor tem uma carreira acadêmica consolidada e tem trabalhado diretamente com questões de ensino de língua na escola. Poderia nos contar como tem sido essa sua atuação?

Carlos Faraco: Nos meus quase cinquenta anos de magistério, atuei em vários níveis de ensino. Na educação básica, o espaço que mais me agradou foi o ensino médio talvez pelos desafios que os adolescentes trazem constantemente para a sala de aula. No ensino superior, atuei tanto como professor de português stricto sensu (em disciplinas voltadas para as práticas de leitura, escrita e oralidade, nas quais pude exercitar e testar minhas crenças de como deve ser esse ensino), quanto como professor de linguística.

Sempre me vi, nesta segunda condição, como formador de professores tentando ensinar a meus alunos como pensar sistematicamente sobre a língua: como observar os fatos, como interpretá-los, como descrevê-los. Sempre quis que meus alunos adquirissem autonomia, ou seja, que levassem consigo das minhas aulas um conjunto de crenças sistematicamente produzidas e um conjunto de procedimentos analíticos de tal modo que 
eles tivessem os recursos necessários para interpretar o que viesse a ocorrer em sua prática docente e para criar alternativas pedagógicas. Não sei quanto consegui alcançar porque nunca tive condições de acompanhar meus alunos em sua vida posterior à universidade. De qualquer forma, a maior dificuldade aqui sempre foi quebrar criticamente as crenças de senso comum e os valores socialmente agregados à língua. O pensamento científico parece estar sempre em desvantagem em relação ao senso comum. Pelo menos no estudo da linguagem verbal e das línguas.

Atuei também na chamada formação em serviço, atendendo professores da rede municipal de Curitiba e estadual do Paraná. As maiores dificuldades aqui eram, de um lado, as lacunas na formação (a experiência universitária tinha significado pouco para muitos deles no sentido de não lhes ter oferecido, de fato, uma mudança no conceitual sobre a língua - continuavam a pensar a língua pelo senso comum) e, de outro, as pressões institucionais (os programas predeterminados e atrelados à avaliação que, em muitos casos, inviabilizavam qualquer inovação).

Por fim, me dediquei também a produzir material didático tanto para o ensino superior quanto para o ensino médio. Nessa atividade, parti sempre do que fazia em sala de aula. Fui transpondo para os livros as práticas que desenvolvia com os alunos. Nesse sentido, os livros espelham, em parte, minhas crenças e práticas pedagógicas.

No caso do ensino superior, como era um trabalho em parceria com colegas, os quatro livros foram escritos e publicados em coautoria - dois com David Mandryk (Português atual e Língua Portuguesa: prática de redação para estudantes universitários) e dois com Cristovão Tezza (Prática de texto e Oficina de texto). Para o ensino médio, escrevi uma coleção monoautoral - Português: língua e cultura - que tem estado no PNLD desde 2005.

Eu diria que a maior dificuldade na produção de material didático foi sempre como encaixar a reflexão gramatical articulada e adequadamente. Nos livros para o ensino superior, focamos só em fatos da norma-padrão. As reflexões se voltam mais para a estrutura textual do que para a estrutura sintática (uma lacuna que reflete, de certa forma, o pouco que temos feito em termos de construção de alternativas pedagógicas concretas).

Na coleção para o ensino médio, tentei fazer de tudo um pouco: exercícios intuitivos, apresentação mais sistemática das classes de palavras e da sintaxe (apresentações que ficaram, no entanto, mais expositivas do que seria desejável, lacuna que, de novo, reflete o pouco que temos feito em termos de uma pedagogia da gramática) e capítulos centrados na norma-padrão/culta. Não posso dizer que estou inteiramente satisfeito com o produ- 
to. Como já disse várias vezes nesta entrevista, temos feito pouco concretamente e temos um longo caminho pela frente. De qualquer forma, é mais fácil criar e praticar alternativas ao vivo em sala de aula (a análise linguística, por exemplo) do que transpor isso para o material didático que, por melhor que seja pensado, não consegue reproduzir a dinâmica da sala de aula, da interação face a face de professor e alunos.

Coelho, Monguilhott e Pires de Oliveira: Muito obrigada!

\section{Referências}

ANTUNES, I. Muito além da gramática: por um ensino de línguas sem pedras no caminho. São Paulo: Parábola, 2007. . Gramática contextualizada: limpando "o pó das ideias simples”. São Paulo: Parábola, 2014.

BAGNO, M. Variação, avaliação e mídia: o caso do ENEM. In: ZILLES, A. M. S.; FARACO, C. A. (Org.) Pedagogia da variação linguística: língua, diversidade e ensino. São Paulo: Parábola, 2015, p. 191-224.

COMÊNIO, J. Didática Magna. Lisboa: Calouste Gulbenkian, 2001.

NEVES, M. H. M. Que gramática ensinar na escola: norma e uso na língua portuguesa. São Paulo: Contexto, 2006. . Texto e gramática. São Paulo: Contexto, 2006.

PIRES DE OLIVEIRA, R.; QUAREZEMIN, S. Gramáticas na escola. Petrópolis: Vozes, 2016.

QUINTILIANO, M. F. Instituição Oratória. Tradução de Bruno F. Bassetto. Tomos I a III (IV). Campinas: Editora da UNICAMP, 2015 e 2016.

VIEIRA, S. R. Três eixos para o ensino de gramática: uma proposta experimental. In: NORONHA, Claudianny A.; SÁ JR., Lucrécio A. Escola, ensino e linguagens. E-book. Natal: EDUFRN, 2017, p. 78-104.

Perguntas enviadas em: 06/082017.

Resposta recebida em: 11/09/2017. 